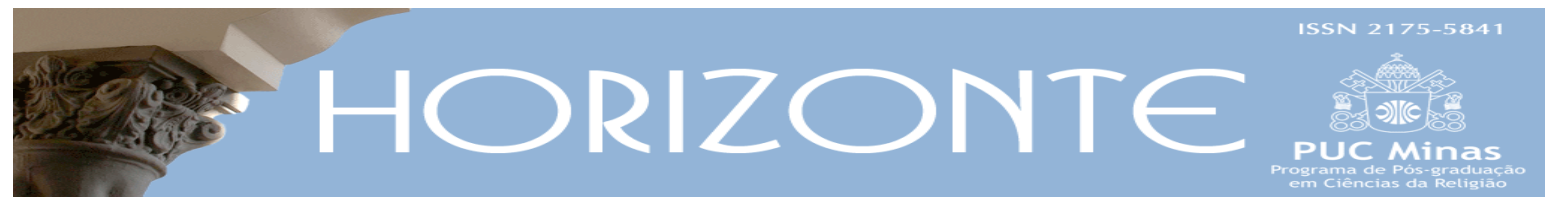

Paper- Comunicação

DOI - 10.5752/P.2175-5841.2015v13n38p1139

\title{
Cartografia de afetos na Amazônia Bragantina
}

\author{
Cartography of affections in the Bragantine Amazon
}

Ênio José da Costa Brito*

\begin{abstract}
Resumo
Esta Comunicação apresenta, de maneira sintética, elementos da etnografia realizada por Jerônimo Silva e Silva, em sua tese de doutorado intitulada Cartografia de afetos na encantaria: Narrativas de Mestres da Amazônia Bragantina. Silva opta por esboçar a etnografia mediante fluxo cartográfico na tentativa de capturar as forças vivas que movimentam Mestres da Amazonia Bragantina. Na hermenêutica dos dados colhidos nas narrativas e convivências com o Pajé-exorcista Cristiano, Pajé Edvaldo, Mãe Terezinha, Mãe Lourdes, Rezadeira Luiza, Mãe Ana e o Experiente Zé Maria desvela uma pluralidade de relações entre pessoas e encantados. Recorre aos conceitos de "corda", "linha" e "viração" para revelar a rica complexidade presente na Religião do Encantados.
\end{abstract}

Palavras-chave: Cartografia de afetos; Memória; Religião dos Encantados; Amazônia Bragantina.

\begin{abstract}
This communication synthetically presents some elements of Jerônimo Silva e Silva's ethnographic research. Actually it is the outlines of his doctoral thesis Cartography of affections in the encantaria: religious masters narratives from Bragantine Amazon. Silva lines out an ethnography via a cartographic flow having in mind to capture its live forces or movers. Using hermeneutics data from these narratives and living with some religious agents in situ - PajéExorcista Cristino, Pajé Edvaldo, Mãe Terezinha, Mãe Lourdes, Rezadeira Luiza, Mãe Ana e Experiente Zé Maria - he unveils a plurality of relationships between people and incantation. Using some local technical concepts like corda (rope), linha (line), viração (breeze) he discloses a rich social complexity in this religion of the incantation.
\end{abstract}

Keywords: Affects cartography; Memory; Incantation Religion; Bragantine Amazon.

Comunicação recebida em 08 de fevereiro de 2015 e aprovada em 07 de abril de 2015.

* Doutor em Teologia. Professor Titular da Pontifícia Universidade Católica de São Paulo. País de origem: Brasil. E-mail: brbrito@uol.com.br.

Horizonte, Belo Horizonte, v. 13, n. 38, p. 1139-1156, abr./jun 2015 - ISSN 2175-5841 


\section{Introdução}

Dia 19 de dezembro, tomei o avião para Belém, seria minha primeira visita à cidade, que, além de suas belezas naturais, encontrava-se toda enfeitada para as comemorações natalinas. O motivo da viagem, participar, a convite do Professor Doutor Agenor Sarraf Pacheco, da banca de doutorado de Jerônimo da Silva e Silva, intitulada Cartografia de Afetos na Encantaria: narrativas de Mestres da Amazônia Bragantina ${ }^{1}$.

O convite me proporcionou uma dupla alegria: reencontrar amigos e amigas e partilhar com professores(as), que considero meus mestres em questões relacionadas com a história e a religiosidade na Amazônia, a leitura feita da tese.

Em tempo natalino, digo que a tese foi um presente. Desembrulhá-lo pediu tempo, mas valeu a pena. Pelo seu teor criativo, pelo perfil interdisciplinar, pela amplidão das questões metodológicas e teóricas levantadas, pelo texto revelador de um minucioso trabalho artesanal, pela extraordinária pesquisa de campo e pelas interpretações dadas aos $\operatorname{dados}^{2}$.

Nossa intenção neste texto é tecer algumas considerações gerais sobre o trabalho, que tem como objetivo "compreender a relação entre pessoas e encantados na iniciação do 'dom'dos'experientes',feitos no fundo' ou 'mestres’3, no

\footnotetext{
${ }^{1}$ A tese foi defendida no dia 22 de dezembro de 2014, no Programa de Pós-Graduação em Antropologia, sendo a banca composta pelos seguintes professores: Dr. Agenor Sarraf Pacheco (Orientador), Dr. Raymundo Heraldo Maués, Dr. Aldrin Moura de Figueiredo, Dra Maria Betânia Barbosa Albuquerque e Dr. Ênio José da Costa Brito

Agradeço ao Prof. Dr Agenor Sarraf Pacheco, que leu a primeira versão deste texto e fez correções e sugestões preciosas para o aperfeiçoamento do mesmo.

${ }^{2}$ Importante que se diga que o campo - Amazônia Bragantina - foi muito generoso com o autor. Muitas vezes, o pesquisador vai a campo e não consegue obter dados satisfatórios. Silva colheu dados que surpreendem o leitor.

${ }^{3}$ Nas palavras do autor: “Carrego o termo 'Mestre' para algumas passagens analíticas da tese e para o título por julgá-lo rico e inteligível na sua dinâmica local: para cada 'Mestre' humano, há um 'Mestre' no campo da encantaria, qual seja, o seu duplo, chamado de 'guia' ou 'chefe de linha', e estes, por conseguinte, agregam multiplicidades de outros seres" (SILVA, 2014, p.16). Tal apreensão revela conexões com concepção geral do mundo da cultura africana, discutido por Hama e Ki-Zerbo (2011, p. 26), ao assinalarem: "Quando vem a noite e o homem se estende sobre sua esteira ou sua cama para dormir, é o momento que seu duplo escolhe para partir (...) É no curso dessas peregrinações que o duplo se choca com as forças do Bem e do Mal, com os bons gênios e com os feiticeiros devoradores de duplos".
} 
interior desse complexo cosmológico" ( SILVA, 2014,p.30)4. Em seguida, percorrer a estrutura da tese, situada no âmbito dos estudos de Antropologia Pós- Moderna, elaborando breves sínteses para que o leitor tenha uma primeira ideia de seu rico conteúdo. Vale lembrar que a perspectiva epistemológica da tese, de tecer investigação na esteira do pensar, fazer e viver cartográfico, ultrapassa a tradiconal ideia de etnografia, herança da ciência moderna. Finalizo a apresentação com um comentário geral sobre o trabalho.

\section{Observações iniciais}

$\mathrm{Na}$ pesquisa, Silva acolheu, no sentido de eligo (escolher), desafios importantes e deu conta deles: como o de mergulhar no complexo cosmológico dos "mestres" da encantaria afroindígena, para estudar "lembranças recompostas e vivências compartilhadas acerca dos ritos de iniciação e incorporação a se manifestar em 'transes', 'mediunidades' ou 'possessões'” (p.29), para rastrear éticas e estéticas "que o pensamento folclorizado ocultou e negou".

O pesquisador acolheu o desafio de acompanhar, na multiplicidade dos corpos e memórias, distintos afetos (p.17) o que possibilitou compreender: o "corpo não como individualidade isolada e desagregada, mas como profundamente relacional" (p.18). "Corpo aberto", "corpo fronteira", "corpo-efeito". Esforço revelador de heranças, de memórias muitas vezes silenciadas e negadas. Enfrentou o desafio de "perceber dinâmicas migratórias e trânsitos culturais entre as travessias nordestinas para o Pará e movências desses líderes religiosos na região, tendo como base de apreensão memórias por eles narradas” (p. 28-29) e, ainda, o de "enfatizar as narrativas orais de praticantes de religiões de matrizes africanas e

\footnotetext{
${ }^{4}$ A partir desta citação indicaremos, apenas, a página da tese. Com relação ao conceito de cosmologia, diz o autor: "entendo cosmologia como a forma com que determinados sujeitos constroem, representam e explicam mediantes múltiplos aspectos do cotidiano - trabalho, sociabilidade e moralidade - os aspectos responsáveis pelo agenciamento e 'ordenamento' da experiência social" (p. 27).
} 
indígenas ao invés de adotar como ponto de partida prioritário, textos e documentos escritos (p. 31), reveladoras do seu interesse na composição e nos processos de memória .

A pesquisa deixa transparecer uma permanente preocupação epistemológica que leva o autor: a reconhecer os limites da "bagagem acadêmica" com que vai a campo (p. 15); mas também a apontar para um renovado paradigma epistemológico: no qual "a epistemologia do sujeito que conhece não desconhece a epistemologia dos sujeitos conhecidos" e ainda se deixa conhecer, ouvir, perceber e ser afetado pela visão do outro (p. 30)5.

Os rastros desta preocupação são muitos: quer compreender como se organizam estas racionalidades diferentes (p. 27); quer compreender a partir de memórias por eles narrados (p. 29); quer construir saberes tendo como base concepções diferenciadas de sentir e perceber (p. 15) ressonâncias ou afetos (p. 206) e quer elaborar uma "etnografia entre" (p. 206).

Tal movimento deixa claro que não há uma única forma de pensar e conhecer, há muitas formas de conhecimento quanto as práticas (SANTOS, 2010), postura que leva o autor não só a compreender o ponto de vista do outro, mas ir além, assumi-lo no processo de conhecimento e deixar-se ouvir e, ainda, buscar na feitura do texto, indeterminar a distinção entre "escrita" e "experiência" (p. 32).

A academia sabe que este é um caminho árduo e pede tempo. Urge lembrar o alerta de Mary Pratt: “a descolonização do conhecimento e da mente é uma tarefa incrível na qual intelectuais e artistas devem permanecer como colaboradores durante gerações" (PRATT,1999, p. 6).

\footnotetext{
${ }^{5}$ Para uma discussão sobre a necessidade de um novo paradigma, ver Brito, 2014, p. 1475-1486. A Dra. Maria Betânia, comentando este dado na arguição, fala de uma contra-epistemologia, uma outra epistemologia.
} 


\section{Veredas de leitura}

(Des)caminhos da iniciação é o título da Introdução (p. 15-45). Nela Silva apresenta aos futuros leitores uma ampla bibliografia sobre estudos relacionados à Amazônia, em especial sobre o tema por ele trabalhado. Oferta generosa, que aponta para o essencial dos estudos feitos por inúmeros pesquisadores, constituindo-se numa introdução ampla e consistente.

O leitor dispõe de uma Introdução criativa, que visa oferecer os dados necessários para uma recepção sensível às nervuras da tese. Numa perspectiva retórica, temos na Introdução uma consistente "capitatio benevolenciae", fundamentada e de perfil analítico.

Na Corda I, intitulada Rizomas entre História e Antropologia (p.46-81) apresenta uma minuciosa revisão bibliográfica, com um objetivo bem definido, oferecer ao leitor a possibilidade de "compreender especificidades da história e cultura amazônica sob o vetor de complexas mesclas ou traduções culturais” (p. $47)^{6}$.

Ao priorizar os registros de interações e trânsitos culturais entre as diversas localidades, explicitou complexidades e especificidades da Religião dos Encantados7, apontando para o dinamismo presente nos diversos estudos provenientes de distintos campos de pesquisa (p. 64); negando simplificações e a existência de práticas puras (p. 69; p. 160); implodindo dicotomias e apontando

\footnotetext{
${ }^{6} \mathrm{Na}$ arguição, Heraldo Maués expressou o desejo de que Silva agrupasse os textos em temas, explicitando os que foram mais utilizados na pesquisa. Observou, também, que é raro encontrar uma etnografia, como a apresentada na tese, informada pela teoria. Destacou a delicadeza de várias passagens, responsáveis pelo perfil poético do texto.

7 Silva acolhe a descrição de "encantado" ou "encantaria" presente no livro organizado por Reginaldo Prandi (2004, p.7-9), o conceito pode ser "enunciado sob o vértice das práticas mágico-religiosas, tendo inúmeras particularidades e que estão sob constante transformação, formando a religião brasileira ou religião dos encantados" (p. 25).
} 
imbricações as mais inusitadas/surpreendentes distantes de um "monoteísmo cientifico" (p. 64) ${ }^{8}$.

Relembra-nos, ainda, que: "a relação entre deuses, entidades e encantados em perene transformação faz das religiões afro-brasileiras em Belém o local do encontro dos encantados, um ponto de fluxo constante de religiosos para o interior do Estado e outras regiões do país" (p. 66).

Na Corda I9, deixou claro, que os estudos sobre a presença negra na Amazônia avançaram muito nos últimos anos, relembra uma das razões deste silêncio: “... a presença negra foi silenciada ou enfraquecida pela forma como pesquisadores paraenses e de outros estados dialogaram com obras de estudiosos como José Veríssimo e Oneida Alvarenga, conforme testificou Aldrin Moura de Figueiredo (2008)" (p. 68). Estes estudos têm superado uma ideia, que por muito tempo foi hegemônica, a de ser a Amazônia só "terra de índio". Trabalham com a preocupação de explicitar tanto os fatores que mais contribuíram para o reconhecimento da presença afro, quanto os que ajudaram a visibilizar populações negras na conformação da sociedade amazônica ${ }^{10}$.

Agenor Sarraf Pacheco, na esteira de outros pesquisadores, tem procurado avançar os estudos desvelando o encontro afroindígena. Termina um de seus artigos dedicado ao tema, relembrando que: "entre silêncios e evidências as culturas amazônicas vão revelando suas múltiplas identidades entre estas a face afroindígena, como matriz constituinte de nosso estar no mundo, não pode ser

\footnotetext{
${ }^{8}$ Expressão de Martin-Barbero (2004, p.15).

9 Para o autor: 'Os termos 'Corda', 'Linha' ou 'Conta', capturados no fluxo etnográfico, apesar de parecerem na lógica do 'dom', expressam intensidades ou especificidades de encantados coagulados no corpo dos mestres humanos, dotando-os de maior ou menor força" (p.11).

10 "Vale lembrar que a maioria dos historiadores que discute escravidão e resistência africana na Amazônia sabe do incômodo causado pela visão que se construiu na historiografia brasileira acerca do lugar inexpressivo do negro na constituição da região" (p. 189).
} 
mais negligenciada" (2012a, p. 18-19) ${ }^{11}$.

Silva nos relembra ainda, que estudos/pesquisas antigas e recentes têm contribuído para desvelar, para dar a conhecer a "identidade pajeística" na Amazônia (p. 56). Estas contribuições têm nos ajudado a vislumbrar as especificidades da identidade ou das identidades.

Impressiona a ambiguidade - não no sentido moral -, que se faz presente na encantaria, que tem um pé na ancestralidade e outro na modernidade (p. 69). Fato que abre para os pesquisadores desafios enormes.

"Entre Jesus Cristo e Índio Guerreiro Caboclo Flechador": Um PajéExorcista em Tempos de Iniciações (p. 82-115) é o titulo da Corda II. A percepção de que os "fenômenos sobrenaturais" que ocorriam em Vila Socorro eram "constitutivos desse universo", "nessas vilas isso é de muito tempo" (p. 95), serviu de moldura para acompanhar o fazer as “contas” - passar pela iniciação -, e o desenvolvimento do aprendizado (p. 92) de Cristiano rezador, exorcista e autentico assistente social ${ }^{12}$.

A história da iniciação de Cristiano é detalhada na fala de dona Joana, mãe do rezador e sempre presente em idas e "missões" espirituais... A história de vida do rezador é tecida no imaginário materno por intermédio do sofrimento que o acompanhou desde a infância; primeiro pelo chamamento xamânico magnetizado pelo olhar de São Jorge na imagem, flexões do catolicismo devocional; segundo na furiosa ação dos "guias" no corpo e alma do "escolhido" - reino dos encantados; e terceiro, e não menos importante, o papel da poderosa rezadora evangélica. Dona Paulina expõe a representação de Jesus como entidade que compartilha junto com os guias e anjos a economia populacional das múltiplas entidades tanto no controle das incorporações recebidas quanto na "doutrinação" e relação "mediúnica" junto ao Índio Guerreiro Caboclo Fechador" (p. 103).

\footnotetext{
${ }^{11}$ Ver também Pacheco, 2010 e 2012b. Nas palavras de Silva: “Em pesquisas realizadas na Amazônia Marajoara, Pacheco (2009) visibilizou a presença de populações negras e ameríndias a partir do século XVII nas escrituras de cronistas, documentos 'oficiais' religiosos, notícias de viajantes, literatos, jornalistas, historiadores e etnólogos do final do século XIX e do séc. XX, bem como depoimentos orais de pajés, pais de santo, leigos engajados e diversos religiosos espanhóis da Ordem dos Agostinianos Recoletos para demonstrar que, no caso marajoara, o regime das águas moldaram fisionomias de encontros e movimentos de populações estrangeiras, diaspóricas e nativas" (p. 70).

${ }^{12}$ Cristiano é "um jovem dotado de especiais propriedades espirituais, pronto para combater espíritos entre o céu e a terra, capaz de não apenas 'exorcizar' essas manifestações espirituais, mas construir sentidos em consonância com os moradores" (p. 85).
} 
Cristiano não só reza, mas se preocupa com as condições de vida das pessoas da comunidade. "Tanto Cristiano quanto as pessoas entrevistadas expõem compreensão de que os 'problemas' que acometiam crianças e adolescentes estavam associados ao conjunto da vida social e não apenas à esfera espiritual” (p. 104).

Na leitura da Corda II, chamou-me a atenção como foi se constituindo a cosmologia de Cristiano, marcada por interconexões, visibilizadas pelas "cordas". Cosmologia entendida pelo autor, "como a forma com que determinados sujeitos constroem, representam e explicam mediantes múltiplos aspectos do cotidiano trabalho, sociabilidade e moralidade - os aspectos responsáveis pelos agenciamento e 'ordenamento' da experiência social” (p. 27).

O autor deixa claro que, para compreender as "cordas", faz-se necessário levar em conta diversas "nervuras", diversos enlaces. Ao longo da leitura da tese toma-se conhecimento da natureza, das características e das funções das "cordas". "A corda não é linear, ordenada. Têm-se linhas fragmentadas, descontínuas" (p. 134); "é e-feito das forças que a seguram e esticam, com todos os atravessamentos possíveis. A corda é e-feito de cortes” (p. 229). Na arguição, Maria Betânia Albuquerque relembrava que "sem as cordas não é possível estabelecer os vínculos e ainda que a retirada das cordas exige saber". Na apresentação da tese, Silva se perguntou: "O que são as cordas? e respondeu: "são linhas que tecem o horizonte da existência”.

Para Cristiano, "qualquer pessoa desavisada ou que "confia demais nos outros" estão entre as que perdem facilmente as "cordas". "Sem elas não é possível manter vínculos com os encantados e apreender as 'doutrinas' pertinentes ao ato de curar" (p. 111).

A Corda III tem como título, Cabocla Jarina: Narrativas de Mãe Terezinha (p. 116-135). Na tentativa de seguir enlaces das "cordas" de Cristiano, recompõe, 
recorrendo a uma "etnografia do encontro", as memórias de Mãe Terezinha, memórias de migração alternadas e fundidas ao processo de sua formação espiritual no quadro cosmológico da Umbanda (p. 117) ${ }^{13}$. Nas palavras do autor:

busquei entender o processo que resultou na formação de seu papel como Mãe-de-Santo, este envolvendo trânsitos espirituais e físicos entre os estados do Ceará e Pará, entrelaçados pela ação de encantados e demais entidades espirituais no corpo de alguns iniciados (p. 117).

No terreiro Oxalá-Xapanã ou "Casa de São Sebastião", de Mãe Terezinha, duas entidades se fazem presentes: o Caboclo Rompe Mato, com suas "linhas quase prontas" e a Cabocla do Fundo Encantado, que tem dificuldade em seguir a "doutrina". "A doutrinação dos caboclos, isto é, a tentativa de ensinar-lhes os princípios dos guias que predominam no terreiro é um processo que depende do gênio (índole) do iniciado e do ‘caboclo encostado’ no seu corpo” (p. 131).

A vivência da entidade no corpo não é um ato, é devir-corpo.

O corpo da iniciada está sendo reconstituído pelos afetos dos encantados para que apreenda manifestações, sinais e mensagens das entidades. Não se trata de um corpo enquanto reflexo da vocação religiosa, nem tão pouco de um corpo apto para receber a entidade, mas da feitura do corpo que seja a entidade (p.125).

A função das cordas é “'segurar' e 'guiar' a 'viração'14 do encantado em gente. Virar gente, desse modo, não significa virar 'humano' e sim adotar perspectiva cósmica de gente, nascer e vir-a-ser em um con-junto neste lado do mundo..." (p. 131).

\footnotetext{
13 "Nascida na cidade de Pedra Branca, Ceará, a narradora - atualmente com 77 anos - descreveu histórias de vida a partir de várias cenas que emergiram no processo de rememoração" (p. 122).

14 “O conceito de 'viração' é enunciado pelos caboclos como 'pedra de toque' do entendimento sobre os processos de iniciação neste terreiro" (p. 126).
} 
Na Corda IV, "Caboclo sem doutrina não è gente (?)": Luzia e os Índios Bravos (p. 136-145) apresenta-nos a figura enigmática de Luzia, rezadeira, que estende "linhas" a encantes no Maranhão. Os fluxos migratórios são responsáveis pela presença de memórias cosmológicas ancestrais em Luzia, a quem foi negada a iniciação pela ausência de doutrina em seus caboclos.

\section{O autor conheceu Luzia,}

enquanto presenciava no Terreiro Oxalá-Xapanã a incorporação seguida de dança e cantoria da Cabocla Jarina, na cabeça de Mãe Terezinha, percebi a demora da Cabocla ao cumprimentar Luzia e o olhar atento e preocupado de uma senhora, apresentada posteriormente como sua genitora (p. 137).

Luzia não se sente bem no terreiro frequentado por sua mãe, ela "considerava os seus caboclos e guias como seres que não precisavam aprender as doutrinas, pois já traziam sabedorias do passado” (p. 140-141). À luz de experiências performativas, Luzia ressignificava rituais apreendidos na Umbanda ${ }^{15}$.

“As 'Linhas' de Luzia espraiam-se, mobilizam e capturam. Tornam-se acoplamentos em cabos, tomadas de celulares e aparelho DVD, devém 'CaboLinha' 'Tomada-Guia'; 'Celular-Terreiro'; 'DVD- Tambor”’ (p. 142).

A presença e a ação do encantado eram garantidas pela música. "A mobilização das encantarias em canções e performances, ao som de múltiplos gêneros musicais, indicou como essa jovem passou a dialogar com tradições familiares de matrizes orais em incorporação de tecnologias no cotidiano" (p. 145).

\footnotetext{
15 Num depoimento dado ao autor, em fevereiro de 2013, ela relata: “Vixe. Quando tinha 12, 13 anos eles (guias) me perseguiam muito, sabe? Eu me trancava no quarto e começava a dançar feito uma doida, dançava muito, muito mesmo. Era Techno, Melody, Rock, Reggae - mais Techno mesmo - que colocava no som da casa bem no alto (volume máximo) (p. 141). Para Silva, as músicas ouvidas e as danças realizadas no quarto representavam uma "performance de negação" das experiências extáticas (p. 142).
} 
No contato com Luzia, o autor constatou, não sem espanto, novas formas de iniciação e religiosidade, que desafiam os estudiosos.

A Corda $V$ tem como título, "Memórias da seca no corpo dos encantados": Terreiro de Mãe Lourdes (p. 146-158). Nela nos reporta às memórias de Mãe Lourdes, mulher enérgica e conciliadora, lembranças compostas a partir de experiências sociais e espirituais no trânsito da experiência migratória (p. 151). Ela como a rezadeira Luzia estende suas 'Linhas' a locais de encante no Maranhão'16.

A Corda se mostra surpreendente pelas narrativas de Mãe Lourdes; pelas conversas do pesquisador com as entidades; pela percepção dos terreiros como locais de trânsito religioso e continuação da sina (p. 157).

Mãe Lourdes deu um extenso depoimento, após realizar um trabalho de cura em uma criança que desmaiava e botava "bichos" pela boca.

Agora esse meu problema é de nascença que veio, porque eu aos sete meses, a meio-dia e depois meia-noite certinho eu chorei na barriga dela, ai eu nasci no dia 7 de setembro às $7 \mathrm{~h}$ da manhã, nasci com um dente no meio da boca, com sete dia de nascida esse dente caiu, depois com sete meses de nascida ela me achou sozinha envergadinha em cima da cama chorando, aí ela disse que ia me dar uma surra com vara de miriti para mim ficar roxa (...) Passou-se um tempo e quanto tinha 15 anos, já no Pará (...) minha tia recomendou muito que eu quando fizesse esta idade fosse mandada para o Maranhão(...) Fui pro Maranhão de novo e quando foi no dia certinho do aniversário esqueceram do aniversário (risos). De manhã cedo falei para mulher de meu pai (dona Guardinha) que ia levar água pros trabalhadores no roçado, pois bem, fui, deixei água e disse pro papai que ia pegar caju (...) demorei, demorei e então papai disse: "que diacho que esta pequena demora tanto? Fragino, vamo comigo achar Lourdes" Hum! Mais na frente papai viu minhas roupa no chão e lembrou-se que era 7 de setembro e gritou: 'AVE-MARIA, FRAGINO, TU NÃO SABE QUE OS BICHO CARREGARAM MINHA FILHA PRO FUNDO?! Eles passavam bem em cima de mim e não me viam, eu também não via eles, os bicho estavam em mim não deixavam eu falar, eu fiquei pertinho dos espinho no canto da cerca, mas também não tava mais em mim, pois para mim eu tava lá era dias, sabe? (p. 149).

\footnotetext{
${ }^{16}$ Num depoimento em julho de 2002 relata: "Olha o meu nome é Lourdes, tenho 62 anos, minha vida é assim, minha casa, meu trabalho e meus dois netos. Somos só nos três. Sou do Maranhão, do Bacuri, mas vivo aqui desde os 12 anos (1963) e até aqui nunca saí do Pará, me formei no trabalho da Umbanda desde os 19 anos e daí sigo os trabalhos" (p. 147).
} 
Dois tópicos me chamaram atenção nesta corda, o da "relação entre corpos", da "transformação de corpos". Relações reveladoras das singularidades dos encontros, dos problemas ou não, isto é, da compatibilidade e incompatibilidade entre corpos dos encantados e do cavalo e vice-versa (p. 153), que resultam no bom encontro ou no mau encontro entre corpo da entidade e corpo do cavalo e viceversa. O segundo tópico, o convite feito para se pensar na "feitura social" dos sujeitos religiosos (p. 150).

Preconceitos e humilhações foram uma constante na vida de Lourdes, mas ela nunca se deixou abater, muito pelo contrário, lutou sempre. Na fala de Silva:

a frequência com que estive na residência de dona Lourdes fez-me perceber que esta mestra da encantaria tinha conflitos que não eram respondidos apenas pela afirmação de ser umbandista, mas também pela maneira como assumiu enfrentar o racismo e o desdém com que muitos olhavam sua condição de pobreza vivida (p.155)17.

O Caboclo Zé Raimundo /vira Mundo e as "Cordas" do pajé Edvaldo é o titulo da Corda VI (p. 159-182) ${ }^{18}$. Nesta corda, de leitura complexa, Jerônimo Silva olha por dentro o processo que leva as pessoas a "domar" a corda dos Caboclos e a se tornarem agentes das entidades. Para realizar este objetivo, ouve atentamente as narrativas de Edvaldo, sobre o processo de "formação" de seus dons espirituais, transes e caboclos incorporados (p. 164).

"Fazer do trânsito não apenas a busca de um iniciador capaz de ajudar a controlar o acesso dos caruanas ${ }^{19}$, mas também de construir no percurso o "fazerse" espiritual pressupõe o entrelaçamento de saberes e ações de mestres com aspectos de uma iniciação coletiva, compartilhada" (p. 164).

\footnotetext{
${ }^{17}$ Silva nos lembra que "durante a etnografia no terreiro de Lourdes não foram poucas rezadeiras e pajés mencionados e presentes no referido local em busca de 'passes'. O universo havia se dilatado. Entre as inúmeras referências, a maioria mencionou as vilas do interior como locais de pajés e umbandistas de 'verdade' (p. 158). Acolhendo esta versão, o autor foi ao encontro do Pajé Edvaldo.

18 "A relação com o jovem pajé Edvaldo Nonato de Souza Filho, 28 anos, foi estabelecida em seis visitas efetivadas entre o mês de maio e agosto de 2013, com intervalos relativos de aproximadamente 15 dias" (p. 163).

${ }^{19}$ Senti falta de uma informação sobre as caruanas. A boa comunicação com as caruanas é necessária para que não haja "cruzar caboclo errado" (p. 168). Para uma boa informação ver, nota 11 em Figueiredo (2009, p. 137)
} 
Edvaldo relata que, após o processo de iniciação de oito meses com uma pajé, que batia tambor em Bragança, deu início à construção do “quartinho/terreirinho" 20 , onde começou seus trabalhos de cura.

No complexo e caro ritual de iniciação, Edvaldo passou por três momentos, cada qual com suas exigências especificas. Para o autor, "estas etapas dos ritos de iniciação apresentavam elaborações que se coadunavam com especificidades das práticas das religiões afro-brasileiras, kardecista, catolicismo ou "pajelança cabocla" (Maués,1990) (167).

O Pajé Edvaldo nos trabalhos, entre outras entidades, incorporava o Caboclo Zé Raimundo Vira Mundo, doutrinado no período de iniciação. Este Caboclo é "dono chefe da cabeça do Cavalo" (p. 166) 21.

O Pajé Edvaldo atuava como um autêntico mediador ao estabelecer um diálogo entre os do "lado de lá” e "os do lado daqui”. "O caboclo Zé Raimundo, por sua vez, afirmara ser tanto morador de 'outros mundos', quanto ter sido encantado no fundo, requerendo constantemente o retorno para o lado daqui. Nesses casos o fundo deságua na margem” (p. 182).

A Corda VII tem como titulo "A nossa vida é um romance": Mãe Ana e a Ciência dos Encantados (p. 183- 207). Nela, através de Mãe Ana, "nascida para rezar", coloca-nos em contato com a "Ciência dos Encantados”22. Frente à rica e complexa experiência de mãe Ana, aponta um desafio para os estudiosos: como acolher "percepções nascidas a partir da lógica dessas cosmologias"?23, isto é,

\footnotetext{
20 "Quartinho-denominado alternadamente de terreiro - é um cômodo de 3 por 4 metros no fundo do quintal, de alvenaria pintado de branco, coberto na parte frontal por telhas artesanais e esteios, com bancos longos de ambos os lados" (p. 168).

21 “O Pajé Edvaldo foi cavalo, dentre tantos outros, dado ao Caboclo Zé Raimundo Vira Mundo desde o nascimento" (p. 180).

22 "Nascida no dia 13 de Agosto de 1913 no Rio grande do Norte, Mãe Ana é Filha de Luis, um tocador de Harmônica (sanfona) que também mucreava (marreteiro) frutas, rapadura, cana-de- açúcar como oito jumentos no interior do Rio Grande do Norte, com Madalena, mãe da narradora, e responsável pela 'banca' de venda" (p. 186).

23 "As conversas com Mãe Ana foram realizadas, basicamente, durante todo o dia, pois os próprios familiares achavam que deveria aproveitar que ela estava lembrando das coisas", sendo raro momentos semelhantes, diziam que havia dado 'sorte'” (p. 184).
} 
"como e de quais premissas partir quando buscamos simetrizar a ciência dos encantados"( p.190).

Com o abandono do pai, no natal de 1919 e a morte da mãe em 1929, Ana passou fome e sofreu nas mãos das irmãs mais velhas (p. 186). Só o casamento com um cearense a livrou do pesadelo.

Os saberes presentes nas práticas de cura de Mãe Ana brotam como resultado de experiência com 'experientes' adquiridos em inúmeros locais por onde percorreu, até a morte do marido, quando mesmo apenas com os filhos continuou por outras andanças (p. 188).

Mãe Ana se tornou uma "rezadeira protetora", para ela "rezar é costurar" (p. 192). Aprendeu com a avó, uma ex-escrava. Mesmo não se identificando com a prática de pajés, Mãe Ana se iniciou nas "linhas”, nas “contas” com as entidades” (p. 196).

Nesta corda, salta aos olhos do leitor a importância dos termos "Virar" e "Desvirar". No inicio da pesquisa, estas noções tinham um peso, à medida que se avançou, elas ganharam uma densidade maior tanto no âmbito da compreensão quanto da prática, ao agregarem novos valores.

A Corda VIII, Entre índios despedaçados e tambores negros do fundo. Zé Maria (p.208-229), Silva apresentou o pajé umbandista, Zé Maria²4, "experiente”, que tem vínculos com dezenas de pajés (p. 217), e não se preocupa com a ação das linhas dos "outros" guias, pois trouxe as suas do fundo, com habilidades para fazer as próprias "linhas". Zé Maria põe o leitor a par das distinções especificas entre o

\footnotetext{
24 "Zé Maria nasceu em Arapiranga, próximo à cidade de Boa Vista em 1915. Muitas são as informações sobre a sua idade, pelos menos seis informantes, entre mães de santo e pajés dizem ter acima de cem anos, uma bisneta, ainda adolescente, esclarece que a data da certidão de nascimento foi emitida em 1915, quando já tinha quase dez anos! (p. 218).
} 
"tirar" os "guias" e o processo de feitura, caracterizado por "amarrar" ou "soltar" (p. 226) $)^{25}$.

Ao longo da leitura da Corda VIII, pensei várias vezes na "Africanização da pajelança na Amazônia" e das suas relações com o mundo indígena, sem esquecer que as Áfricas se reproduziram no Brasil de diversas maneiras. A pesquisa de campo convida o leitor a pensar estas relações ou, mais especificamente, a refletir como levar em conta nos encontros as referências culturais religiosas de cada uma destas manifestações.

Um outro tópico que chama a atenção é o da relação dos encantados com o espaço e o tempo. Encontramos no texto referências ao lugar dos encantados, a áreas especificas ocupadas por eles (p. 212; p. 215). Quanto ao tempo, discutido pelo autor na corda II, afirma que os encantados detêm uma noção de tempo (p. 94), fala-se de uma "temporalidade relacional".

O texto toca, também, num tema recorrente em ambientes mediúnicos, o do enfraquecimento do dom, da sua diminuição. Momento de sofrimento e risco para pajés e mães-de-santo. Na Corda anterior já se comentava que Mãe Ana não gosta de falar sobre a diminuição de suas rezas, fato que atribuiu à idade (p.199-200). Zé Maria atribuía ao excesso de trabalho.

\section{Notas finais}

Nada melhor, ao finalizar esta Comunicação - que apresentou alguns tópicos da tese, consciente de ter apontado apenas um pouco da rica pesquisa realizada - do que dar a palavra aos membros da banca: Raimundo Maués chamou atenção para a originalidade de vários capítulos e para o cuidado com o

\footnotetext{
25 O próprio Silva nos relata como chegou a Zé Maria: “Foi justamente conversando com um jovem 'médium' da 'Linha Espírita', chamado de Amilton, em Quatipuru, sobre o lugar de respeito e proeminência do Encantado D. Sebastião e Cabocla Jarina na região, e com a informação de que apenas os mais 'experientes' recebiam ou falavam com esses'encantes', emergiu na memória o pajé mui 'forte' de Quatipuru, citado às expensas por Mãe Ana. O seu nome é Zé Maria" (p. 207).
} 
qual o autor cruzou autores clássicos da antropologia com o trabalho de campo; Maria Betânia referiu-se à tese como uma história que nos afeta, que nos sensibiliza e Aldrin Figueiredo afirmou tratar-se de um doutorado não convencional, que apresenta uma narrativa renovada e enfrenta questões novas em que a etnografia emerge como roubo e a tese como encosto. Agenor Sarraf (orientador) ao comentar a sessão, reafirmou uma vez mais a qualidade acadêmica do trabalho desenvolvido pelo doutorando e apontou novos horizontes de estudo.

Cartografia de afetos na Encantaria constitui-se num novo ponto de partida para os pesquisadores das religiões afro-brasileiras na Amazônia. Ter-se colocado à escuta de Mestres da Encantaria Amazônica possibilitou a emergência de um mundo, atravessado por múltiplas forças reveladoras de uma cosmologia que não fatia, não divide, mas integra a realidade e situa os seres humanos entre os outros seres.

O diálogo com homens e mulheres da Religião dos Encantados revelou um pathos existencial, portador de uma sabedoria ancestral, que se visibiliza nas práticas de iniciação, aprendizado, "domação" e "feitura".

Jerônimo Silva captou bem as nuances e rugosidades do diálogo entre os "mestres humanos" e o "mestres encantados" ou "mestres do fundo", levando o leitor a compreender o "fazer-se espiritual" dos agentes da Encantaria.

Cartografia de afetos na Encantaria aponta para inúmeras possibilidades de pesquisas interdisciplinares, investigações necessárias e desafiadoras, pois implicam no respeito às especificidades das diversas áreas envolvidas.

Digno de nota, o ter explicitado, ainda, a dimensão pedagógica presente na atuação de alguns mestres na iniciação dos aprendizes, atuação que nos lembra o aforisma do Padre Antônio Vieira, no Sermão do Espírito Santo: "Para ensinar sempre é necessário amar e saber, porque quem não ama não quer, e quem não sabe não pode". 
A insistência do autor nas trajetórias individuais de pajés, mães-de-santo e rezadeiras ajuda-nos a entender melhor não apenas aspectos que tocam a religião, como dimensão simbólica e como experiência de vida diária, mas também questões relacionadas com a medicina, a cura e a política.

O autor toma o leitor pelas mãos e desembaralha com ele os conceitos de "corda", "linha” e "viração" para desvelar a rica complexidade presente na Religião dos Encantados.

Cartografia de afetos na Encantaria apresenta um conjunto de imagens, desenhadas no contínuo etnográfico, que não só ilustram o texto, mas o complementam. Numa futura publicação, que esperamos ocorra em breve, tendo em vista os futuros leitores, seria conveniente acrescentar um índice remissivo e breve glossário.

Leitura recomendada para todos os que se interessam por conhecer um pouco mais o universo plural amazônico com sua diversidade no plano epistêmico, religioso, ético e cosmológico.

\section{REFERÊNCIAS}

BRITO, E. J. C. Desafios para a construção de uma epistemologia do Sul. In: CONGRESSO INTERNACIONAL DA SOTER, 27, Espiritualidades e Dinâmicas Sociais: Memória e Prospectiva, Belo Horizonte. Anais ... Belo Horizonte: SOTER, 2014, p. 1475-1486.

Disponível em: w.soter.org.br/eventodinamico/index.php?evento=9

FIQUEIREDO, A. M. A cidade dos Encantados: Pajelança, feitiçaria e religiões afrobrasileiras na Amazônia. Belém: Edulfba, 2009.

HAMA, B.; KI-ZERBO, J. Lugar da história na sociedade africana. In: KI-ZERBO, J. (editor) Metodologia e pré-história da África. Tradução MEC; Centro de Estudos AfroBrasileiros da Universidade Federal de São Carlos. 3. ed. São Paulo: Cortez; Brasília: UNESCO, 2011, p. 23-35. 
MARTÍN-BARBERO. J. Oficio de Cartógrafo: travessias Latino-Americanas da comunicação na cultura. São Paulo: Loyola, 2004.

MAUÉS, R. H. A ilha encantada: medicina e xamanismo. Belém: UFPA,1990.

PACHECO, A.S. En el Corazón de la Amazonía: identidades, saberes e religiosidades no regime das águas marajoaras. Tese de Doutorado. Programa de Estudos Pós-Graduados em História Social, Pontifícia Universidade Católica. São Paulo, 2009.

PACHECO, A.S. Os Estudos Culturais em outras margens: identidades Afroindígenas em 'Zonas de Contato" Amazônicas. Fênix - Revista de História e Estudos Culturais, Uberlância, v. 9, n. 3, p. 1-20, $2012 \mathrm{a}$.

PACHECO, A.S. Cosmologias Afroindígenas na Amazônia Marajoara. Projeto História, São Paulo, v. 44, n. 2, p. 197-226, 2012 b.

PACHECO, A. S. Encantarias Afroindígenas na Amazônia Marajoara: narrativas práticas de cura e (in)tolerâncias religiosas. Horizonte, Belo Horizonte, v. 8, n. 17, p. 88-92, abr./jun. 2010;

PRATT, M. L. Os olhos do Império: relatos de viagem e transculturação.Bauru: Edusc, 1999.

PRANDI, R. Encantaria Brasileira: o livro dos mestres, caboclos e encantados. Rio de Janeiro: Pallas, 2004.

SANTOS, Boaventura de S; MENESES, Maria P. (Org..) Epistemologias do Sul. São Paulo: Cortez, 2010.

SILVA, Jerônimo da Silva e. Cartografia de afetos na Encantaria: narrativas de Mestres da Amazônia Bragantina. 2014. Tese (Doutorado) - Universidade Federal do Pará, Programa de Pós-graduação em Antropologia, Belém. 